\title{
Campus Energy Use Prediction (CEUP) Using Artificial Intelligence (AI) to Study Climate Change Impacts
}

\author{
Soheil Fathi ${ }^{1}$, Ravi Srinivasan ${ }^{1}$, Robert Ries ${ }^{1}$ \\ ${ }^{1}$ University of Florida, Gainesville, FL, USA
}

\begin{abstract}
When managing the energy performance of a portfolio of buildings over time, climate change can be a threat as it can cause significant changes in energy use patterns. This paper uses artificial intelligence techniques to develop an AI-based forecasting tool, Campus Energy Use Prediction (CEUP) that can help managers to forecast campus future monthly energy use under various climate scenarios. We have leveraged historical energy use data of buildings in the University of Florida, Gainesville, FL to develop CEUP. CEUP was then used to forecast the impact of climate change with the average outdoor temperature of the median, hottest, and coldest years of future climate scenarios of Gainesville, FL as input.
\end{abstract}

\section{Introduction}

Global environmental challenges have led city governments to gradually modify their policies and decisions towards green and energy efficient approaches. Governments have set ambitious goals in reducing their Greenhouse Gas (GHG) emissions, such as $80 \%$ by 2050 in New York (2014) and Boston (2014).

During recent decades, a vast range of national level energy forecasting models have been developed in a disaggregated way, varying considerably regarding data input requirements and socio-technical assumptions about buildings operation. Therefore, their expected results vary considerably based on these assumptions. Suitable understanding of the limitations and capabilities of these models would benefit both building scientists and policy makers. Such knowledge would help policy makers to determine which building parameters are important for national carbon reduction and to come up with more effective adaptation strategies (Kibert, 2016). On the other side, construction professionals could also benefit from this knowledge in developing techniques and business strategies for sustainable refurbishment.

Improvements in computer science and technology has made computers reliable and common tools in design and assessment of buildings. Also, the speed and accuracy of computer calculations make them important tools contributing to the engineering aspects of building design process. As a result, computer simulations are extensively implemented in the design and operation of buildings (Berardi, 2017). Energy simulation models are essentially used for the design and forecasting of building energy performance. However, optimization models are not frequently used in designing building energy performance, due to the complexity of building systems and their dynamic thermal behaviour. Yet, as today's computers are growing more and more capable, systematic prediction and optimization approaches are becoming more feasible to achieve building energy performance forecasting and assessment (Song et al., 2017).

The purpose of this paper is to develop a CEUP tool for predicting the effects of long-term climate change on buildings energy performance using $\mathrm{AI}$ techniques. The tool comprises of four steps namely, Data Collection, AI Development, Model Validation, and Model Implementation, and can predict the energy use of campus buildings with almost $90 \%$ accuracy. We have relied on energy use data of buildings situated in the University of Florida, Gainesville, FL. To study the impact of climate change, we have used climate properties of three future weather files of Gainesville, FL, developed by the North American Regional Climate Change Assessment Program (NARCCAP) represented based on their impact: median (year 2063), hottest (2057), and coldest (2041).

\section{Background}

Considering the potentials beyond individual building scale, urban planners, civil engineers, and construction managers can considerably contribute to form energy efficient cities (Song et al., 2017). However, the problem includes complex details making the solution to be difficult. According to United Nations (World Population Prospects, 2017), by 2050, two-thirds of the world's population will be urban, increasing the negative effects of climate change as well as the importance of seeking practical solutions.

In the European Union (EU), residential buildings consume $22 \%$ of total energy. Policy makers have recognized this sector's potential to contribute towards lowering energy consumption and $\mathrm{CO} 2$ emissions (EPBD, 2003). Therefore, several policies and directives have been issued in order to enhance building energy performance. The main purpose of such policies is to improve buildings energy performance through requirements such as calculation of buildings integrated energy performance, application of minimum criteria for new and renovated buildings, energy performance certifications, and HVAC systems inspection.

Raising interests in accurate building energy performance simulation tools, as well as the traditional focus on 
developing certification procedures, show the interests of experts and researchers in assessing the energy performance of individual buildings rather than large building stocks. However, in order to achieve the desired global environmental goals, it is extremely important to focus on buildings energy performance at a regional, urban, or national scale (Santamouris et al., 2001).

On the aggregate, buildings operational energy demand has a fundamental share in urban level energy consumption. Such demands are highly dependent on thermo-physical and space functionality properties of the buildings, as well as the climate of their surrounding environment, which constantly changes over time (Cozen et al., 2018). In order to satisfy these demands, community managers should have a comprehensive understanding of the nature of buildings energy performance and be able to evaluate this performance both in real-time and in the future. Effective data-driven decision-making tools are helpful in providing such evaluation potential (Amasyali and El-Gohary, 2018).

Accurate energy forecasting methods have various advantages in planning and optimization of buildings energy use at individual or urban scale. For new buildings, without any energy consumption history, computer simulation methods are used for energy analysis and forecasting possible future scenarios (Hong and Luo, 2018). However, for existing buildings with available historic time series energy data, statistical and machine learning approaches can be faster and much more accurate (Deb, et al., 2017). Once a building is occupied and operating, various factors with complex interactions influence its energy behaviour. Therefore, accurate simulation of buildings using energy simulation software is extremely difficult.

Use of data-driven techniques can fundamentally help in forecasting the energy performance of existing buildings (Reinhart and Davila, 2016; Wang and Srinivasan, 2017). These techniques rely on building's historic data in order to model its future energy use patterns. Fast computation of historic data, being suitable for non-linear models, and higher accuracy levels comparing to deterministic models, are among the advantages of data-driven approaches. However, they are highly dependent on historic data, difficult to generalize, and non-transparent (Eisenhower, et al., 2012; Zhuang et al., 2015). According to our review of more than 70 journal papers relevant to the applications of Machine Learning (ML) in Building Energy Use Prediction (BEUP) in both individual building and aggregate urban levels, published in the last four years (2015 - 2018), common ML practices cover the majority of methods used in BEUP. We have considered 14 ML methods that were used in BEUP. These methods are Artificial Neural Networks (ANN), Support Vector Regression (SVR), Multiple Linear Regression (MLR), Genetic Algorithms (GA), Random Forests (RF), Cluster Analysis (CA), Bayesian Networks (BN), Gaussian Processes (GP), Gradient Boosting (GB), Principal Component Analysis (PCA), Deep Learning (DL), Reinforcement Learning (RL), Auto-Regressive Integrated Moving Average (ARIMA), and Ensemble
Prediction (ENS). Majority of ML methods use mathematical models of sample (or training) data, in order to make predictions or decisions when the nature of the data is not completely known. Figure 1 Shows the percentage of each method used in individual and urban level BEUP research conducted in the last four years (2015-2018). It can be seen that in BEUP research, ANN, SVR, and RF methods have been used much more frequently than Reinforcement Learning or ARIMA.

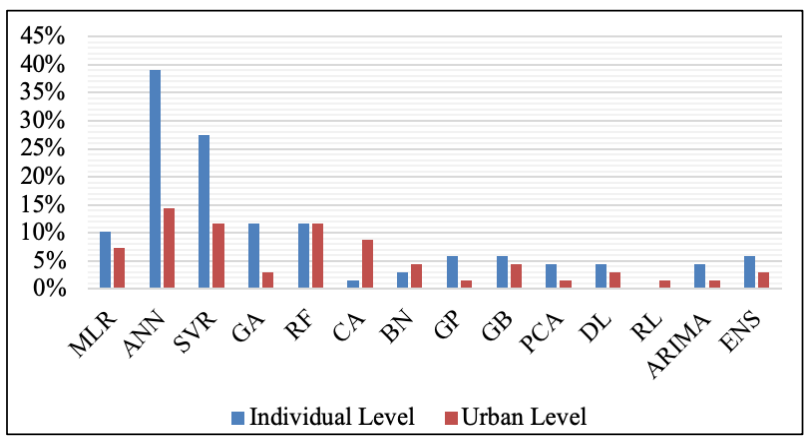

Figure 1: Usage percentages of ML methods in BEUP.

Also, MLR, RF, GB, and DL are fairly used in both study levels, while methods such as ANN or SVR have been used more frequently in individual level BEUP, and methods like CA or BN have been used more frequently in urban level BEUP. The results also, show that reinforcement learning has not been used in individual level BEUP in the past 4 years, which may be due to the complexity of the approach. Furthermore, the scarcity of research in urban versus individual level BEUP is considerable.

As examples of frequent ML use in urban level BEUP, An et al. (2018) used clustering and statistical analyses to represent air conditioning use patterns for more than 300 residential buildings in Zhengzhou, China, using building Key Performance Indicators (KPI). Sokol et al. (2017) used $\mathrm{BN}$ to develop a new methodology in defining different archetypes in urban building energy models. They defined unknown or uncertain parameters in archetype descriptions as probability distributions and used measured energy data to update these distributions by Bayesian calibration. Jovanovic et al. (2015) used feed forward back propagation ensemble neural networks for predicting buildings daily heating energy demands at urban level, using temporal and spatial input properties. For each ANN type, they analysed three models, using different number of input parameters, in order to improve prediction accuracy. Hsu (2015) compared a cluster-wise regression to common two-stage algorithms that use Kmeans and model-based clustering with linear regression, in order to predict annual urban building energy consumption. Their results showed that K-means method gives more stable clusters when the correct number of clusters is chosen. Kontokosta and Tull (2017) used RF, SVR, and energy source feature selection to predict annual Energy Use Intensity (EUI) of city buildings. Robinson et al. (2017) used RF, SVR, and GB on Commercial Buildings Energy Consumption Survey (CBECS) to predict annual energy consumption of commercial buildings in New York City. Nutkiewicz et 
al. (2018) tested the impacts of geometric designs and physical efficiency retrofits on building energy consumption of commercial and educational buildings in a dense urban area for multiple temporal and spatial scales, using EnergyPlus (E+) simulation, ANN, DL, and residual networks. Beccali et al. (2017) used a two-layer ANN with multilayer perceptron in order to develop an easy-to-use decision support tool, to rapidly forecast the total energy consumption of commercial and educational buildings. They used a large set of data, obtained from the energy audits of 151 existing public buildings located in four regions of south Italy. Contrasting regression, ARIMA approach does not require a set of predictor variable and only needs the target variable, yet showing appropriate levels of accuracy (i.e. Lu 2015)

Besides individual and urban levels, we classified the literature according to four other criteria: 1. Building Type, 2. Energy Type, 3. Input Data, and 4. Time Scale. Various levels of these criteria have been used for applying ML methods in BEUP, and there has been no solid proof or measure that a specific method or criterion performs better than the others. Furthermore, the scarcity of research in urban versus individual level BEUP is quite noticeable. This study focuses on the use of AI in campus building energy forecasting. The main purpose of the research is to develop a Campus Energy Use Prediction (CEUP) tool for assessing the effects of long-term climate change using AI techniques.

\section{CEUP Model Development}

This section discusses the CEUP model development. CEUP uses a four-layer structure consisting of, (1) Data Collection, (2) AI Development, (3) Model Validation, and (4) Model Implementation, shown in Figure 2.

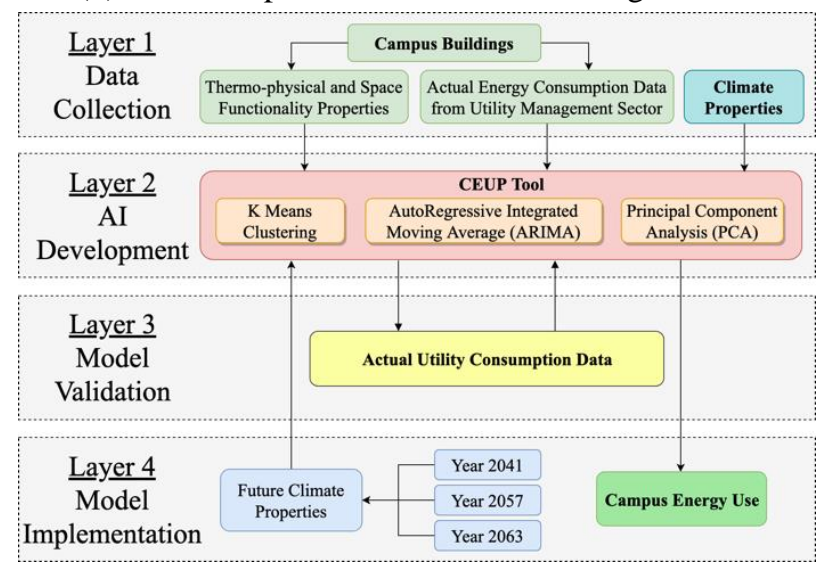

Figure 2: CEUP General Structure.

Layer 1 refers to collecting buildings specifications data, as well as their total monthly utility consumption, consisting of electricity, chilled water, steam, and natural gas. In addition, local monthly average outdoor temperatures have been collected. In Layer 2, the AIbased energy use prediction model has been developed using k-means Clustering, PCA, and ARIMA techniques. In the third layer, the CEUP model has been validated using representative buildings actual energy consumption data. Finally, in the fourth layer, campus energy use has been predicted, using three future climate scenarios, developed by NARCCAP, that represent the median, hottest, and coldest annual average temperatures. Each layer is explained in more detail in the following sections.

\section{Layer 1: Data Collection}

University of Florida (UF) has a 2,000-acre campus and more than 900 buildings. According to the campus utility data obtained from UF's Physical Plant Division (PPD), there are a total of 217 buildings with a sensor configuration which captures an individual buildings' utility consumption every 15 minutes. UF also provided access to the documentation of the building's energy performance for various energy performance rating systems such as the US Green Building Council's (USGBC) Leadership in Energy and Environmental Design (LEED) rating system. Reviewing energy rating documentation varying from preliminary design plans to as-built plans and LEED V4 forms, we could derive some of the thermo-physical properties which influence buildings energy performance. Twelve buildings had with the required information available. The set includes various primary building functions such as educational, residential, research laboratory, and sport facilities.

Four types of data were collected for this research namely, (A) space functionality characteristics; (B) building thermo-physical properties including lighting and equipment energy intensities; (C) building energy use; and (D) historic and future weather data.

A) Space functionality characteristics are determined using the percentages of different functional spaces in every building, which are calculated for each building used in this study. Offices, classrooms, teaching labs, research areas, auditoriums, gymnasiums and residential areas are some of the functional spaces used for this classification. For instance, Rinker Hall (Bldg. ID 0272), which houses UF's School of Construction Management, consists of $14 \%$ classrooms and $19 \%$ office areas, while Cypress Hall Student Housing (Bldg. ID 0086) has only $5 \%$ office areas and $56 \%$ residential areas. The space classification percentages are based on the Gross Square Meters (GSM) area of the buildings (Fathi and Srinivasan, 2015). Table 1 represents the list of space functionality percentages used in this study.

B) The building thermo-physical properties that we could derive from the energy performance documents, and can be seen in Table 2, are total Gross Square Meters (GSM), number of floors, exterior walls $\mathrm{U}$-value $\left(\mathrm{W} / \mathrm{m} 2{ }^{\circ} \mathrm{C}\right)$, windows $\mathrm{U}$-value $\left(\mathrm{W} / \mathrm{m} 2{ }^{\circ} \mathrm{C}\right)$, window to wall ratio, Solar Heat Gain Coefficient (SHGC), floors U-value $\left(\mathrm{W} / \mathrm{m} 2{ }^{\circ} \mathrm{C}\right)$, roof $\mathrm{U}$-value $\left(\mathrm{W} / \mathrm{m} 2{ }^{\circ} \mathrm{C}\right)$, Lighting Power Density (LPD) (W/m2), and Equipment Power Density (EPD) $(\mathrm{W} / \mathrm{m} 2)$.

C) Monthly utility consumption for the twelve buildings were collected for 3 years (36 months) from Jan.2015 to Dec. 2017. The buildings are various ages. The purpose of choosing a 3-year time period was to make sure that data is available for all the buildings over the analysis time period. The consumption values are in kilowatt hour (kWh). 
D) Monthly average outdoor temperatures $\left({ }^{\circ} \mathrm{C}\right)$ for UF campus were collected from Florida Automated Weather Network (FAWN).

\section{Layer 2: AI Development}

This section describes how the model is tested and validated for AI model implementation. In order to forecast the energy performance of buildings based on their historic consumption data and thermo-physical properties, we have implemented k-means clustering, PCA, and ARIMA forecasting methods. We assume our initial energy consumption function to be as equation 1 :

$$
\text { Campus Energy Consumption }=\mathrm{F}+\mathrm{G}
$$

where $\mathrm{F}$ is a nonlinear function of buildings thermophysical properties and $\mathrm{G}$ is a time series function of buildings historic energy consumption data. Due to the small number of buildings that we could use, solving the $F$ part of the equation for these many properties was not feasible ( $\mathrm{n}$ equations for $\mathrm{m}$ unknowns, while $\mathrm{m}>\mathrm{n}$ ). Using PCA, we defined eight new variables which are a combination of the initially introduced variables. The defined variables are as follows:

1. Building Thermo-physical Properties: 1.1. Total Uvalue $\mathrm{x}$ Area $\left(\mathrm{W} /{ }^{\circ} \mathrm{C}\right), 1.2$. Windows SHGC x Area (m2), and 1.3. Total Power (W).

2. Space Functionality Percentages: 2.1. Classroom, 2.2. Office, 2.3. Residential, 2.4. Teaching labs, and 2.5. Research labs.

Here, variable 1.1 is the sum-product of exterior wall and windows $\mathrm{U}$-values and their surface areas in $\left(\mathrm{W} /{ }^{\circ} \mathrm{C}\right)$, variable 1.2 is the sum-product of window SHGC and their surface area in $(\mathrm{m} 2)$, and variable 1.3 is the total building lighting and equipment power in Watts (W). Also, using PCA, five space functionality categories that have the highest effect on buildings' energy consumption were identified.

Table 1: Buildings Space Functionality Percentages.

\begin{tabular}{|c|c|c|c|c|c|c|c|c|c|c|c|c|}
\hline $\begin{array}{l}\text { 응 } \\
\frac{\dot{\theta 0}}{\infty}\end{array}$ & 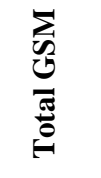 & 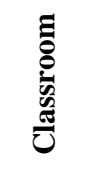 & 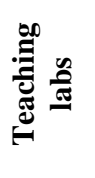 & 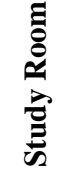 & 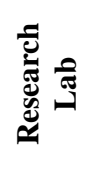 & 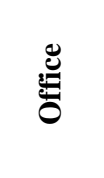 & 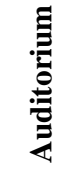 & 离 & 芑充 & 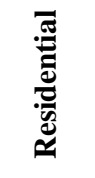 & के & 乙它 \\
\hline 0028 & 8,243 & $5.5 \%$ & $0.0 \%$ & $0.0 \%$ & $50.5 \%$ & $11.7 \%$ & $0.0 \%$ & $0.0 \%$ & $0.0 \%$ & $0.0 \%$ & $0.0 \%$ & $32.3 \%$ \\
\hline 0064 & 6,756 & $21.5 \%$ & $0.6 \%$ & $3.2 \%$ & $0.0 \%$ & $20.6 \%$ & $0.0 \%$ & $0.3 \%$ & $0.0 \%$ & $0.0 \%$ & $0.0 \%$ & $53.8 \%$ \\
\hline 0081 & 2,196 & $1.4 \%$ & $0.0 \%$ & $1.4 \%$ & $0.0 \%$ & $51.7 \%$ & $0.0 \%$ & $0.7 \%$ & $0.0 \%$ & $0.0 \%$ & $0.0 \%$ & $44.8 \%$ \\
\hline 0086 & 7,911 & $0.0 \%$ & $0.0 \%$ & $0.0 \%$ & $0.0 \%$ & $5.2 \%$ & $0.0 \%$ & $0.0 \%$ & $0.0 \%$ & $56.1 \%$ & $0.0 \%$ & $38.7 \%$ \\
\hline 0110 & 1,582 & $53.5 \%$ & $0.0 \%$ & $7.5 \%$ & $0.0 \%$ & $10.1 \%$ & $0.0 \%$ & $0.0 \%$ & $0.0 \%$ & $0.0 \%$ & $0.0 \%$ & $28.9 \%$ \\
\hline 0214 & 7,942 & $20.0 \%$ & $13.5 \%$ & $7.0 \%$ & $0.5 \%$ & $12.1 \%$ & $1.5 \%$ & $0.0 \%$ & $0.0 \%$ & $0.0 \%$ & $0.0 \%$ & $45.4 \%$ \\
\hline 0272 & 5,235 & $14.4 \%$ & $18.6 \%$ & $0.0 \%$ & $0.0 \%$ & $25.2 \%$ & $0.0 \%$ & $0.0 \%$ & $0.8 \%$ & $0.0 \%$ & $0.0 \%$ & $41.0 \%$ \\
\hline 0289 & 1,710 & $0.0 \%$ & $0.0 \%$ & $0.0 \%$ & $0.0 \%$ & $0.0 \%$ & $0.0 \%$ & $0.0 \%$ & $0.0 \%$ & $66.5 \%$ & $0.0 \%$ & $33.5 \%$ \\
\hline 0764 & 1,800 & $26.1 \%$ & $19.0 \%$ & $0.0 \%$ & $0.0 \%$ & $12.5 \%$ & $0.0 \%$ & $0.0 \%$ & $0.0 \%$ & $0.0 \%$ & $0.0 \%$ & $42.4 \%$ \\
\hline 0860 & 7,879 & $0.0 \%$ & $0.0 \%$ & $0.0 \%$ & $0.0 \%$ & $0.0 \%$ & $0.0 \%$ & $0.0 \%$ & $0.0 \%$ & $0.0 \%$ & $99.0 \%$ & $1.0 \%$ \\
\hline 1375 & 11,126 & $0.0 \%$ & $1.4 \%$ & $0.4 \%$ & $1.0 \%$ & $32.1 \%$ & $5.3 \%$ & $0.0 \%$ & $0.0 \%$ & $0.0 \%$ & $0.0 \%$ & $59.8 \%$ \\
\hline 1377 & 8,642 & $0.0 \%$ & $0.0 \%$ & $0.0 \%$ & $31.4 \%$ & $24.8 \%$ & $0.0 \%$ & $0.0 \%$ & $0.7 \%$ & $0.0 \%$ & $0.0 \%$ & $43.1 \%$ \\
\hline
\end{tabular}

Table 2: Building thermo-physical properties.

\begin{tabular}{|c|c|c|c|c|c|c|c|c|c|}
\hline $\begin{array}{c}\text { Bldg. } \\
\text { ID }\end{array}$ & $\begin{array}{c}\text { Total } \\
\mathbf{G S M} \\
\mathbf{( m 2})\end{array}$ & $\begin{array}{c}\text { Number } \\
\text { of } \\
\text { Floors }\end{array}$ & $\begin{array}{c}\text { W/W } \\
\text { Ratio }\end{array}$ & $\begin{array}{c}\text { Exterior } \\
\text { Wall U-value } \\
\left(\mathbf{W} / \mathbf{m} \mathbf{2}^{\circ} \mathbf{C}\right)\end{array}$ & $\begin{array}{c}\text { Windows } \\
\mathbf{U} \text {-value } \\
\left(\mathbf{W} / \mathbf{m} \mathbf{2}^{\circ} \mathbf{C}\right)\end{array}$ & $\begin{array}{c}\text { Windows } \\
\mathbf{S H G C}\end{array}$ & $\begin{array}{c}\text { Roof U-value } \\
\left(\mathbf{W} / \mathbf{m} \mathbf{2}^{\circ} \mathbf{C}\right)\end{array}$ & $\begin{array}{c}\text { LPD } \\
(\mathbf{W} / \mathbf{m} \mathbf{2})\end{array}$ & $\begin{array}{c}\text { EPD } \\
(\mathbf{W} / \mathbf{m} \mathbf{2})\end{array}$ \\
\hline 0028 & 8,243 & 2 & 0.138 & 0.3878 & 3.0810 & 0.30 & 0.2714 & 6.1354 & 18.08334 \\
\hline 0064 & 6,756 & 4 & 0.203 & 0.2220 & 5.1104 & 0.50 & 0.1447 & 9.9162 & 10.7639 \\
\hline 0081 & 2,196 & 3 & 0.19 & 0.2986 & 1.5331 & 0.38 & 0.2839 & 13.4548 & 16.1459 \\
\hline 0086 & 7,911 & 5 & 0.254 & 0.2285 & 2.4416 & 0.24 & 0.1493 & 5.9202 & 9.6875 \\
\hline 0110 & 1,582 & 2 & 0.072 & 0.2271 & 3.9180 & 0.38 & 0.3406 & 10.3010 & 18.2986 \\
\hline 0214 & 7,942 & 5 & 0.231 & 0.7041 & 4.2586 & 0.25 & 0.2725 & 9.9027 & 28.2014 \\
\hline 0272 & 5,235 & 3 & 0.372 & 0.2328 & 1.4195 & 0.28 & 0.1817 & 2.4756 & 10.7316 \\
\hline 0289 & 1,710 & 2 & 0.13 & 0.3236 & 4.0883 & 0.65 & 0.2157 & 15.9306 & 79.6529 \\
\hline 0764 & 1,800 & 1 & 0.221 & 0.6813 & 1.4763 & 0.38 & 0.2271 & 12.9167 & 5.3819 \\
\hline 0860 & 7,879 & 1 & 0.182 & 0.7041 & 4.2586 & 0.60 & 3.7419 & 12.3785 & 5.3281 \\
\hline 1375 & 11,126 & 3 & 0.41 & 0.1589 & 1.9135 & 0.35 & 0.2044 & 10.8716 & 15.8229 \\
\hline 1377 & 8,642 & 5 & 0.31 & 0.2328 & 2.6574 & 0.81 & 0.2612 & 12.3785 & 7.7501 \\
\hline
\end{tabular}


The buildings are clustered into similar building types using a k-means approach in order to reduce the complexity of forecasting, so that there is no need to model each and every building on campus in order to assess its energy performance. Also, building clusters are used in extrapolating representative building energy use to campus energy use. K-means is usually used for cluster analysis in data mining. It aims to partition $\mathrm{n}$ observations into k clusters in which each observation fits to the cluster with the closest mean, that is the cluster prototype. Figure 3 shows the results of clustering buildings based on their thermo-physical and space functionality properties, using k-means clustering.

Here, each axis is a unit-less function of the eight independent variables that we defined in our study. The reason for using such functions is simply that we are unable to map each of the buildings in an 8-dimensional space. Therefore, we need to use these functions to map the buildings in a 2-dimensional space. As a result, we could partition the buildings into four clusters of educational (yellow), residential (green), research

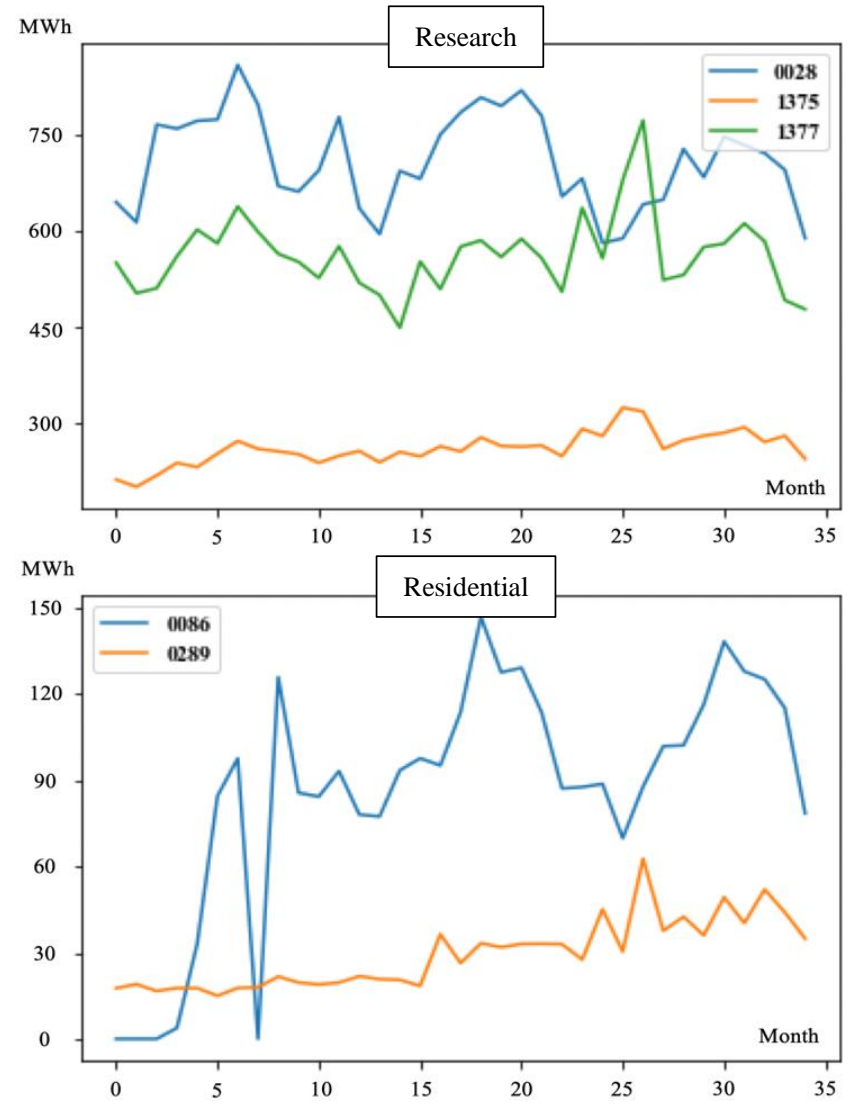

Figure 4: Partitioning buit

Figure 4 shows the 3 -year (2015-2017) monthly total energy consumption in MWh for buildings within each of the clusters. Defined clusters are of type research, sport, residential, and educational respectively. The relative similarity of the consumption patterns over time for the buildings within a cluster can be seen in this figure.

PCA is a multivariate statistical approach for assessing the correlations existing among a set of inter-correlated variables. Being able to categorize complex and highly inter-correlated set of variables, PCA gives a better (purple), and sport (blue) buildings. We can observe that buildings with similar space functionalities and thermophysical properties are located closer to each other in the k-means clustering 2-dimensional map.

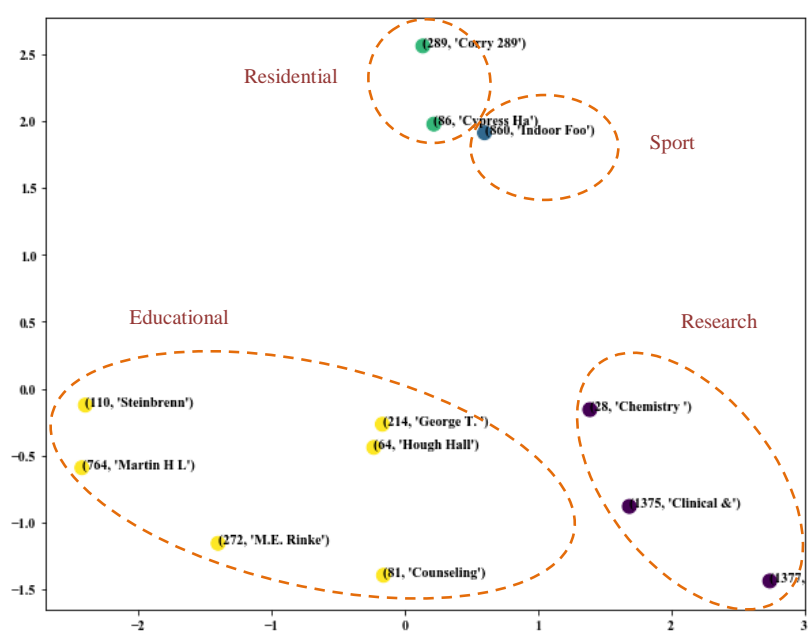

Figure 3: Buildings clustering using k-means approach.
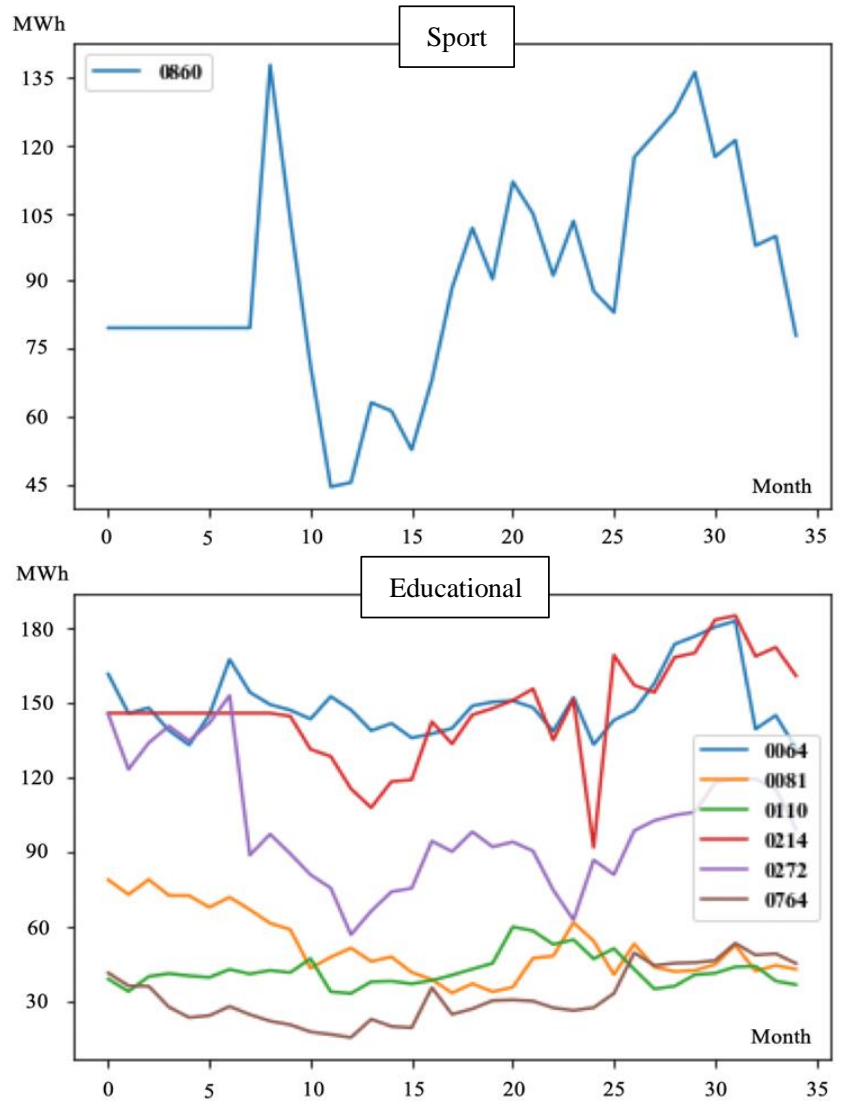

uildings into four clusters.

understanding of cause and effect relationships. Tardioli et al. (2018) used PCA, k-means clustering, and RF to identify representative buildings and building groups in a set of commercial urban buildings using building typology, construction period, district location, building final use and geometric information. We have conducted PCA in order to prioritize the eight independent variables over all the thermo-physical and space functionality variables shown in Tables 1 and 2. based on their effects on campus building energy consumption. 
ARIMA models are the most typical model of time series prediction methods. Lu et al. (2015) used ARIMA, ANN, and SVR to predict the hourly electricity, heating, and cooling energy consumption of a set of community sports buildings, in which they took into account building heterogeneity to improve forecast accuracy. Initially, ARIMA forecasting was conducted for each cluster prototype representing the average amount of energy consumption of buildings within each cluster. Here, the training size is $75 \%$ of the available data and the testing size is $25 \%$. After training, the overall energy consumption of buildings could be forecasted using their cluster prototype for 2018. Our dependent variable is the total monthly energy consumption normalized by the average outdoor temperature in each month in order to include the effects of this climate variable in our model.

As a measure of accuracy, we have used Mean Squared Error (MSE). We calculated the error percentages by dividing MSE by the cluster representative building energy consumption which is the average amount of energy consumption of buildings within each cluster. Table 3 shows the comparison of output errors of the forecasting results.

Table 3: Comparison of prediction error percentages.

\begin{tabular}{|c|c|c|}
\hline \multirow{2}{*}{ Bldg. ID } & \multicolumn{2}{|c|}{ MSE/Mean Percentage } \\
\cline { 2 - 3 } & ARIMA & PCA + ARIMA \\
\hline 0028 & 8.13 & 8.87 \\
\hline 0064 & 15.60 & 12.16 \\
\hline 0081 & 30.19 & 20.37 \\
\hline 0086 & 19.68 & 17.48 \\
\hline 0110 & 18.62 & 11.40 \\
\hline 0214 & 16.29 & 12.66 \\
\hline 0272 & 17.18 & 17.17 \\
\hline 0289 & 13.50 & 10.70 \\
\hline 0764 & 27.17 & 4.49 \\
\hline 0860 & 20.12 & 17.64 \\
\hline 1375 & 29.62 & 21.05 \\
\hline 1377 & 8.87 & 6.38 \\
\hline
\end{tabular}

Based on this comparison, we can conclude that in the majority of buildings, conducting PCA with ARIMA forecasting would result in better accuracy. Also, it should be noted that PCA reduces the dimension of input variables significantly and hence results in better accuracy. Consequently, in order to increase the model accuracy levels, instead of forecasting only based on cluster representative buildings, we conduct PCA and ARIMA for all the 12 buildings used in this study.

\section{Layer 3: Model Validation}

To make CEUP more reliable, we need to validate it with buildings' actual energy use. Validation process is essential in order to produce realistic energy use predictions. Our validation method follows these steps:

1. Comparing CEUP with buildings' actual energy use

2. Calculating validation measures (i.e. RMSE, etc.)

3. Comparing the validation measures to the allowable range according to building energy codes.

For validation of CEUP monthly energy forecasting, according to availability of actual energy consumption data, we have used the monthly data from year 2017. Figure 6 shows actual versus CEUP simulated energy use for the educational cluster representative, UF Rinker School of Construction Management.

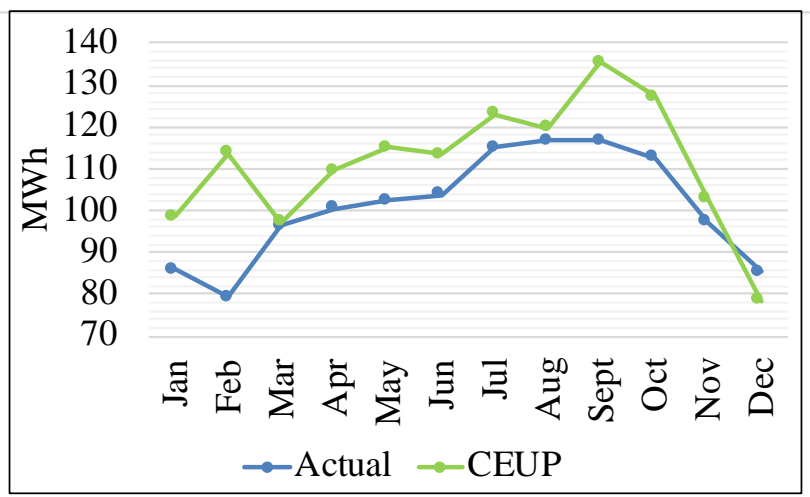

Figure 6: Actual versus CEUP simulated energy

Referring to ASHRAE guidelines, the acceptable range of CV(RMSE) for monthly validation is $\pm 15 \%$. Table 4 shows the CV(RMSE) calculations for actual energy use versus CEUP simulations for Rinker Hall. The calculated $14.1 \% \mathrm{CV}-\mathrm{RMSE}$ is within the acceptable ranges of ASHRAE code.

Table 4: CV(RMSE) for actual vs. CEUP results in $M W h$ for Rinker Hall, the Educational cluster representative.

\begin{tabular}{|c|c|c|}
\hline & Actual & CEUP \\
\hline Jan & 85.95 & 98.45 \\
\hline Feb & 79.23 & 113.69 \\
\hline Mar & 96.38 & 97.28 \\
\hline Apr & 100.35 & 109.59 \\
\hline May & 102.43 & 115.16 \\
\hline Jun & 103.67 & 113.40 \\
\hline Jul & 115.13 & 123.07 \\
\hline Aug & 116.71 & 119.84 \\
\hline Sept & 116.66 & 135.38 \\
\hline Oct & 112.69 & 127.17 \\
\hline Nov & 97.07 & 102.55 \\
\hline \multirow[t]{2}{*}{ Dec } & 85.42 & 78.52 \\
\hline & CV(RMSE) & $14.1 \%$ \\
\hline
\end{tabular}

Accordingly, the CV-RMSE for actual energy use versus CEUP simulations for research, sport, and residential cluster representative buildings are calculated as $9.22 \%$, $8.3 \%$, and $9.13 \%$, meeting ASHRAE requirements and validating CEUP acceptable levels of accuracy.

\section{Layer 4: Model Implementation}

Table 5 shows the CEUP simulated monthly energy consumption values in MWh for the twelve buildings used in this study. The total energy consumption simulated with the CEUP tool for year 2018 is calculated as 26,676 MWh for the twelve buildings. According to campus buildings utility consumption data collected from UF PPD as well as campus buildings space functionality percentages, we can extrapolate the consumption of this set of buildings to the entire UF campus, based on the cluster buildings GSM, and predict 2018 campus energy consumption to be $812,560 \mathrm{MWh}$.

NARCCAP is an international program that serves the high-resolution climate scenario needs of the United States, Canada, and northern Mexico, using regional climate model, coupled global climate model, and time- 
slice experiments. In order to estimate campus operational energy consumption under long-term climate change, three future climate scenarios of median (year 2063), hottest (year 2057), and coldest (2041) annual average temperature are used. As CEUP monthly energy consumption forecasts are normalized by the average outdoor temperature in each month, we could predict the annual campus energy use for the three future climate scenarios, based on the average outdoor temperature values. Considering campus actual energy consumption in year 2018 as the comparison baseline, the results in MWh can be found in Table 6 .

Table 5: CEUP simulated monthly energy consumption (MWh) for the twelve buildings used in the study.

\begin{tabular}{|c|c|c|c|c|c|c|c|c|c|c|c|c|c|c|}
\hline \multicolumn{2}{|c|}{ Bldg. ID } & $\mathbf{0 0 2 8}$ & $\mathbf{0 0 6 4}$ & $\mathbf{0 0 8 1}$ & $\mathbf{0 0 8 6}$ & $\mathbf{0 1 1 0}$ & $\mathbf{0 2 1 4}$ & $\mathbf{0 2 7 2}$ & $\mathbf{0 2 8 9}$ & $\mathbf{0 7 6 4}$ & $\mathbf{0 8 6 0}$ & $\mathbf{1 3 7 5}$ & $\mathbf{1 3 7 7}$ & Totals \\
\hline Month & Tavg & & & & & & & & & & & & \\
\hline $2018-1$ & 14.91 & 567.8 & 130.0 & 53.3 & 86.6 & 46.3 & 89.9 & 97.3 & 37.0 & 25.5 & 78.6 & 266.2 & 544.6 & 2023.1 \\
\hline $2018-2$ & 16.57 & 574.9 & 139.6 & 40.1 & 68.2 & 50.3 & 165.0 & 115.5 & 15.2 & 25.2 & 66.6 & 301.9 & 664.1 & 2226.7 \\
\hline $2018-3$ & 16.72 & 626.8 & 143.5 & 52.2 & 85.7 & 42.2 & 153.3 & 92.4 & 34.6 & 27.0 & 87.9 & 283.9 & 755.2 & 2384.5 \\
\hline $2018-4$ & 21.04 & 634.1 & 153.9 & 43.1 & 99.4 & 34.5 & 150.5 & 110.7 & 14.5 & 24.2 & 97.3 & 231.2 & 511.4 & 2104.9 \\
\hline $2018-5$ & 23.78 & 711.5 & 169.3 & 41.3 & 99.7 & 35.6 & 164.2 & 119.5 & 18.8 & 24.5 & 101.9 & 244.0 & 519.2 & 2249.5 \\
\hline $2018-6$ & 25.15 & 668.3 & 172.4 & 41.8 & 113.6 & 40.1 & 165.8 & 112.3 & 12.6 & 25.6 & 110.5 & 250.9 & 561.8 & 2275.7 \\
\hline $2018-7$ & 26.57 & 730.2 & 176.0 & 44.1 & 135.0 & 40.7 & 178.8 & 127.3 & 25.7 & 25.8 & 92.2 & 255.4 & 566.9 & 2398.1 \\
\hline $2018-8$ & 26.63 & 717.4 & 178.3 & 51.7 & 124.8 & 43.2 & 180.5 & 115.8 & 14.9 & 30.4 & 93.9 & 262.1 & 597.7 & 2410.6 \\
\hline $2018-9$ & 24.91 & 705.1 & 136.1 & 41.5 & 122.2 & 43.4 & 164.6 & 138.2 & 27.4 & 27.1 & 72.1 & 240.6 & 570.5 & 2288.9 \\
\hline $2018-10$ & 21.57 & 679.5 & 141.5 & 43.7 & 112.4 & 37.6 & 168.1 & 122.4 & 20.5 & 29.2 & 75.1 & 250.9 & 480.4 & 2161.3 \\
\hline $2018-11$ & 16.60 & 575.0 & 128.6 & 42.2 & 76.6 & 36.2 & 156.9 & 102.3 & 7.7 & 23.2 & 49.7 & 211.6 & 466.7 & 1876.7 \\
\hline $2018-12$ & 16.02 & 666.3 & 148.4 & 60.5 & 85.5 & 53.8 & 147.7 & 79.7 & 18.7 & 25.7 & 92.6 & 275.6 & 621.7 & 2276.2 \\
\hline
\end{tabular}

Table 6: Average outdoor temperature and campus energy use for baseline and future climate scenarios.

\begin{tabular}{|c|c|c|c|c|c|}
\hline Year & 2018 & 2018 & 2041 & 2057 & 2063 \\
\hline Scenario & Actual & CEUP & Coldest & Hottest & Median \\
\hline $\begin{array}{c}\text { Avg. } \\
\text { Outdoor } \\
\text { Temp. } \\
\left({ }^{\circ} \mathrm{C}\right)\end{array}$ & 21.17 & 21.17 & 19.82 & 22.18 & 20.99 \\
\hline $\begin{array}{c}\text { Campus } \\
\text { Energy } \\
\text { Use } \\
\text { (MWh) }\end{array}$ & 752,858 & 812,560 & 780,262 & 901,999 & 838,458 \\
\hline $\begin{array}{c}\text { Compared to baseline } \\
\text { actual use }\end{array}$ & $+7.93 \%$ & $+3.64 \%$ & $+19.81 \%$ & $+11.37 \%$ \\
\hline
\end{tabular}

It can be seen that the variation of campus energy use in the upcoming 40 years, based on NARCCAP future weather scenarios, can be between $+3.64 \%$ to $+19.81 \%$, and should be managed accordingly.

\section{Conclusion}

This study develops a data-driven campus-scale energy use prediction, namely CEUP tool, which implements artificial intelligence in order to assess the effects of longterm climate change. CEUP model development consists of 4 layers of (1) Data Collection, (2) AI Development, (3) Model Validation, and (4) Model Implementation. We have relied on energy use data of buildings situated in the University of Florida, Gainesville, FL. To study the impact of climate change, we have used average outdoor temperature of three future climate weather files of Gainesville, FL, represented based on their impact: median (year 2063), hottest (2057), and coldest (2041). According to our results, CEUP is a credible tool for predicting campus energy use, and given various possible climate scenarios, CEUP can be helpful to campus energy managers to plan their future energy needs. CEUP has the capacity to be updated with additional buildings and be incorporated with various climate variables in order to be used as a comprehensive decision-making tool for city and building portfolio managers. Also, new buildings which are going be added to the community can be designed based on optimized building thermo-physical and space functionality specifications, in order to better participate in the reduction of their environmental footprints. Therefore, CEUP can not only be a decision making but a sustainable design tool, helpful to designers. The next steps are to obtain more building data as well as introducing more independent variables to increase the accuracy levels of the model. As more building data is collected and analyzed, other climate variables such as relative humidity, and solar radiation will be incorporated into the model to improve prediction accuracy. In addition, shifting the modeling time intervals from months to hours and simulating the buildings energy performance in an hourly basis will also increase accuracy (Fathi and Srinivasan, 2019). Furthermore, as the number of buildings is increased, it is likely that the number of clusters will also increase, expanding the range of building functionality types within campuses, communities, and cities. Such practices can help in improving accuracy and provide a more accurate energy use prediction under various climate scenarios.

\section{References}

Amasyali, K., and El-Gohary, N. M. (2018). A review of data-driven building energy consumption prediction studies. Renewable and Sustainable Energy Reviews 81 (2018): 1192-1205.

An, J., Yan D., and Hong, T (2018). Clustering and statistical analyses of air-conditioning intensity and 
use patterns in residential buildings. Energy and Buildings 174: 214-227.

ASHRAE Standards Committee. (2002). ASHRAE guideline 14, measurement of energy and demand savings. Atlanta.

Beccali, Marco, et al. (2017). Artificial neural network decision support tool for assessment of the energy performance and the refurbishment actions for the non-residential building stock in Southern Italy. Energy 137 (2017): 1201-1218.

Berardi, U. (2017). A cross-country comparison of the building energy consumptions and their trends. Resources, Conservation and Recycling 123 (2017): 230-241.

City of Boston (2014). Greenovate Boston. 2014 climate action plan update. Boston: City of Boston.

City of New York (2014). One city built to last. New York: City of New York. Mayor's Office of LongTerm Planning and Sustainability.

Cozen, B, et al. (2018). Energy communication: theory and praxis towards a sustainable energy future. Environmental Communication 12.3: 289-294.

Deb, C., et al. (2017). A review on time series forecasting techniques for building energy consumption. Renewable and Sustainable Energy Reviews 74: 902.

Eisenhower, B., et al. (2012). A methodology for metamodel based optimization in building energy models. Energy and Buildings 47: 292-301.

EPBD Directive 2002/91/EC (2003). Directive of the European parliament and of the council on the energy performance of buildings. The European Community Official Journal 2003;L001:0065-71.

Fathi, S. and Srinivasan, R.S. (2015). Analysis of energy performance of university campus buildings using statistical and energy modeling approaches. Proceedings of the 2015 Winter Simulation Conference. IEEE Press.

Fathi, S. and Srinivasan, R.S. (2019). Climate Change Impacts on Campus Buildings Energy Use: An AIbased Scenario Analysis. Proceedings of the 1st ACM International Workshop on Urban Building Energy Sensing, Controls, Big Data Analysis, and Visualization. ACM, 2019.

González, P.A., and Zamarreno J.M. (2005). Prediction of hourly energy consumption in buildings based on a feedback artificial neural network. Energy and Buildings 37.6: 595-601.

Hong, T, and Luo, X. (2018). Modeling Building Energy Performance in Urban Context. ASHRAE BPAC Conference, Chicago, IL.

Hsu, D. (2015). Comparison of integrated clustering methods for accurate and stable prediction of building energy consumption. Applied energy 160: 153-163.
Jovanovic, R. Z., Sretenovic, A. A., and ZivkoviC, B. D. (2015). Ensemble of various neural networks for prediction of heating energy consumption. Energy and Buildings 94 (2015): 189-199.

Kibert, C. J. (2016). Sustainable construction: green building design and delivery. John Wiley \& Sons.

Kontokosta, C. E., and Tull, C. (2017). A data-driven predictive model of city-scale energy use in buildings. Applied energy 197 (2017): 303-317.

Lu, X, et al. (2015). Modeling and forecasting energy consumption for heterogeneous buildings using a physical-statistical approach. Applied Energy 144 (2015): 261-275.

Nutkiewicz, A., Yang, Z., and Jain, R. K. (2018). Datadriven Urban Energy Simulation (DUE-S): A framework for integrating engineering simulation and machine learning methods in a multi-scale urban energy modeling workflow. Applied Energy 225 (2018): 1176-1189.

Reinhart, C. F., and Davila, C. C. (2016). Urban building energy modeling - A review of a nascent field. Building and Environment 97 (2016): 196-202.

Robinson, C., et al. (2017). Machine learning approaches for estimating commercial building energy consumption. Applied Energy 208 (2017): 889-904.

Santamouris, M., et al. (2001). On the impact of urban climate on the energy consumption of buildings. Solar energy 70.3: 201-216.

Sokol, J., Davila C.C., and Reinhart C.F. (2017). Validation of a Bayesian-based method for defining residential archetypes in urban building energy models. Energy and Buildings 134: 11-24.

Song, H., Srinivasan, R.S., Jeschke, S., and Sookoor, T. (2017). Smart Cities: Foundations, Principles and Applications. John Wiley \& Sons.

Tardioli, G., et al. (2018). Identification of representative buildings and building groups in urban datasets using a novel pre-processing, classification, clustering and predictive modelling approach. Building and Environment 140: 90-106.

United Nations DESA Population Division (2017). World Population Prospects. https://population.un.org/wpp/.

U.S Energy Information Administration. (2018). Annual Energy Outlook 2018 with Projections to 2050.

Wang, Z., and Srinivasan, R.S. (2017). A review of artificial intelligence based building energy use prediction: Contrasting the capabilities of single and ensemble prediction models. Renewable and Sustainable Energy Reviews 75: 796-808.

Zhuang, J., et al. (2015). Building cooling load prediction based on time series method and neural networks. International Journal of Grid and Distributed Computing 8.4. 